\title{
Serial Monitoring of Antidepressant Response to Electroconvulsive Therapy with Sleep EEG Recordings and Dexamethasone Suppression Tests
}

\author{
L. Grunhaus, D. Tiongco, H. Roehrich, A. Eiser, M. Feinberg, and \\ J.F. Greden
}

\section{Introduction}

The study of the biological correlates of major depressive disorder (MDD) has received great impetus in recent years. Electroencephalographic (EEG) sleep measurements and the Dexamethasone Suppression Test (DST) have been among the most studied and productive of these biological correlates. Commonly described EEG sleep abnormalities in MDD include shortened rapid eye movement (REM) latency, increased REM density, decreased delta sleep, decreased sleep efficiency, and decreased total sleep time (Kupfer and Thase 1983; Gillin et al. 1984). With EEG sleep measurements, used individually or through discriminant analysis, the sensitivity, specificity, and diagnostic confidence for primary endogenous depression ranges from $61 \%$ to $90 \%, 80 \%$ to $100 \%$, and $83 \%$ to $100 \%$, respectively (Kupfer and Thase 1983). Similar findings have been described for the DST in MDD (Carroll et al. 1981). Thus, both the sleep EEG and the DST can be used to support the

From the Department of Psychiatry, University of Michigan Psychiatric Hospitals, Ann Atbor, MI.

Supported in part by NIMH Grant MH 19875 and by the Department of Psychiatry, University of Michigan.

Address reprint requests to Dr. L. Grunhaus, Department of Psychiatry, University of Michigan Psychiatric Hospitals, 1405 East Ann Street, Ann Arbor, MI 48109.

Received November 9, 1984; revised February 12, 1985. clinical diagnosis of MDD with a significant degree of confidence.

A second important application of the biological correlates of MDD is in the monitoring of the antidepressant treatment response. Normalization of the DST in patients treated with tricyclic antidepressants (Greden et al. 1983) or electroconvulsive therapy (ECT) (Albala et al. 1981) has been shown to occur consistently with the clinical improvement of the patients. Sleep EEGs, however, have not been used for the monitoring of the antidepressant response because of the marked effects most psychotropics have on sleep EEG measurements (Gillin et al. 1984). Although preliminary findings (Kupfer et al. 1976; Kupfer 1981) suggest that the effects of initial dosages of amitriptyline on sleep EEG variables can be used to predict antidepressant treatment response, these effects of amitriptyline may reflect its anticholinergic action rather than its antidepressant effects.

ECT can provide a model with which to study the effects of treatment on the sleep EEG measurements in a setting that is almost devoid of the unwanted effects of psychotropic medications. When given alone, modified only by very short-acting barbiturates, muscle relaxants, and quaternary anticholinergics, a course of ECT may allow us to monitor the sleep EEG changes occurring with clinical improvement.

We report a case in which serial sleep EEGs 
and DSTs were used in conjunction with clinical depression ratings to monitor the antidepressant response to a course of unilateral ECT. The changes in the biological correlates paralleled those of the clinical measurements and normalized with treatment. We will discuss previous experience with the use of serial sleep EEG in the monitoring of the antidepressant response to ECT.

\section{Case Report}

The patient is a 61-year-old divorced, white female with three previous episodes of MDD. The current episode of illness began approximately 1 year before admission. Throughout the year, the patient was treated with several antidepressants without significant clinical response. The patient presented symptoms of depressed mood, pathologic guilt with associated delusions of having caused serious mental illness in one daughter and major medical illness in a granddaughter, and crying spells when speaking about her family's alleged illnesses. She also had nihilistic delusions of financial ruin and was convinced she was unable to continue living because of her poor economic situation. She complained of middle and terminal insomnia, poor appetite, a 10-lb weight loss, lack of enjoyment of most of her activities, anergia, and mild somatic anxiety, but no hypochondriacal symptoms. She described herself as being totally unfunctional at home, which was confirmed by her family. The patient denied suicidal ideation.

She was diagnosed as having MDD, endogenous subtype with psychotic features, and was considered to be a good candidate for ECT. The patient received our standard evaluation, including: (1) a 16-day drug-free period, (2) a comprehensive medical and psychiatric examination, (3) the review of previous medical documentation, (4) a Schedule for Affective Disorders and Schizophrenia (SADS) interview, (5) an interview with the family of the patient, and (6) joint clinical diagnosis achieved by consensus between the primary clinician, the SADS interviewer, and the senior psychiatrist.
EEG sleep recordings and the 1-mg overnight DST were performed according to the methods of Feinberg et al. (1982) and Carroll et al. (1981), respectively. A discriminant function (Feinberg et al. 1982) based on REM density and REM latency was calculated for the patient: a score of less than 1 is suggestive of endogenous depression. Sleep EEGs were performed on days $1,2,11,25,32,43$, and 44 , and ECT treatments began on day 8 and were given 3 times a week for a total of 14 right unilateral treatments. Baseline sleep EEGs were performed in the patient's own hospital bed after a drug-free period of 16 days; the serial sleep recordings were performed on the second night following the ECT treatment. The DST was performed once a week, with the patient receiving the dexamethasone 48-72 hr before the sleep EEG recording and not on ECT days. The final sleep EEGs were performed 3 and 4 days after the last ECT treatment. The patient did not receive medication other than succinylcholine, glycopyrrolate (quaternary anticholinergic agent), and sodium methohexital as modifiers of the ECT treatment.

\section{Results}

The results presented in Table 1 show that both biological correlates were confirmative of the MDD diagnosis. The DST was above the $5 \mu \mathrm{g} / \mathrm{dl}$ cutoff line, and the REM latency and discriminant functions were all well within the described MDD scores. With ECT treatments we see a slow but steady decrease in the Hamilton Rating Scale for Depression scores (HRSD), indicating clinical improvement. The changes in the sleep measurements began to occur after the second ECT treatment. Unfortunately, because of technical problems with the sleep recording, we were able to obtain only the REM latency on this night. At week 6, after 8 ECT treatments, both the HRSD scores and the DST remained within the "non-normalized" ranges, whereas the sleep measurements improved. DST results normalized 1 week after the 14th ECT treatment. Normalization of DST in this patient was slower than that described by Albala et al. (1981). Other sleep EEG measurements, viz., early 
Table 1. Serial Monitoring of Sleep EEG and DST and Weekly Depression Ratings in a Psychotic Patient Treated with ECT

\begin{tabular}{|c|c|c|c|c|c|c|}
\hline \multirow[b]{2}{*}{ Week } & \multirow{2}{*}{$\begin{array}{c}\text { Cumulative } \\
\text { ECT }\end{array}$} & \multirow{2}{*}{$\begin{array}{l}\text { Highest } \\
\text { DST }\end{array}$} & \multirow[b]{2}{*}{ HRSD } & \multicolumn{3}{|c|}{ Sleep EEGs } \\
\hline & & & & $\mathbf{R L}^{a}$ & $\mathrm{RD}^{b}$ & $\mathrm{DF}^{c}$ \\
\hline 1 & - & 4.48 & 25.0 & - & - & - \\
\hline \multirow[t]{2}{*}{2} & - & 9.99 & 22.5 & 24 & 3.97 & $(-0.3)$ \\
\hline & & & & 19 & 4.05 & $(-0.5)$ \\
\hline 3 & - & 6.89 & 19.0 & - & - & - \\
\hline 4 & 2 & 9.94 & 25.5 & 39 & $?^{d}$ & $?^{d}$ \\
\hline 5 & 5 & 5.01 & 20.5 & - & - & - \\
\hline 6 & 8 & 7.68 & 16.0 & 56 & 2.65 & 1.1 \\
\hline 7 & 10 & 13.21 & 16.0 & 62 & 2.14 & 1.4 \\
\hline \multirow[t]{2}{*}{8} & 14 & 6.32 & 9.0 & 66 & 2.05 & 1.6 \\
\hline & & & & 82 & 2.53 & 2.0 \\
\hline 9 & 14 & 3.09 & 7.0 & - & - & - \\
\hline
\end{tabular}

${ }^{a} \mathrm{RL}, \mathrm{REM}$ latency.

${ }^{h} \mathrm{RD}, \mathrm{REM}$ density

'DF, discriminant function: $<1=$ endogenous; $>1=$ nonendogenous.

${ }^{d}$, Missing data.

morning awakenings, sleep latency, number of arousals, delta sleep, and sleep efficiency, did not show significant changes with treatment.

\section{Discussion}

Serial monitoring of biological correlates of endogenous depression suggest that it is possible to relate the antidepressant treatment responseas measured by rating scales-to biological changes. This has been shown to occur with the DST during the treatment of melancholic patients; the changes in the DST (from nonsuppression to suppression) correlate with the clinical changes (Albala et al. 1981; Greden et al. 1983).

The serial monitoring of antidepressant response with sleep EEG recordings is less frequently studied because of the effects psychotropic medications have on sleep measurements. Modified ECT may provide a good model in which to study the effects of antidepressant treatment (ECT) on serial sleep EEG recordings.

The existing reports on the effects of ECT on sleep EEGs all date from 10 to 15 years ago and are difficult to interpret. Nevertheless, all of the studies (Green and Stajduhar 1966; Hawkins et al. 1967; Zarcone et al. 1967; Van de
Castle and Hawkins 1969; Mendels et al. 1974) comment on the beneficial effects of ECT on sleep EEG parameters, particularly those of increased total sleep time, increased stage 4 or delta sleep, increased REM sleep, and decreased number of awakenings. The effects of ECT on REM latency are less clear. Green and Stajduhar (1966) reported a case of a psychotically depressed patient followed with multiple sleep EEG recordings and depression rating scales. The authors reported initial low dream latency and high depression ratings. Following a course of ECT, the dream latency increased significantly and the patient became euthymic. The findings of Green and Stajduhar were not confirmed by other authors (Hawkins et al. 1967; Zarcone et al. 1967; Van de Castle and Hawkins 1969; Mendels et al. 1974); these discrepancies are probably secondary to different sleep scoring methods, and more importantly, may be due to the use of REM suppressant medications during the recordings. Our findings with the serial sleep EEG recordings are similar to those reported by Green and Stajduhar 20 years ago.

In our patient, we show the normalization of two biological correlates - sleep EEG and DSTwith ECT treatment. Our findings suggest that serial monitoring with sleep EEGs in patients 
with MDD undergoing ECT treatment may be of use and can complement the DST monitoring. Before any further comment can be made on this use of the sleep EEG, systematized studies need to be done, and these are currently in progress in our laboratory.

\section{References}

Albala AA, Greden JF, Tarika J, Carroll BJ (1981): Changes in serial dexamethasone tests among unipolar depressions receiving electroconvulsive treatment. Biol Psychiatry 16:551-560.

Carroll BJ (1982): The dexamethasone suppression test for melancholia. Br J Psychiatry 140:292-304.

Carroll BJ, Feinberg M, Greden JF, Tarika J, Albala A, Haskett R, James N, Kronfol Z, Lohr N, Steiner M, deVigne P, Young E (1981): A specific laboratory test for the diagnosis of melancholia. Arch Gen Psychiatry 38:15-22.

Feinberg M, Gillin JC, Carroll BJ, Greden JF, Zis AP (1982): EEG studies of sleep in the diagnosis of depression. Biol Psychiatry 17:305-316.

Gillin JC, Sitaram N, Wehr T, Duncan W, Post R, Murphy DL, Mendelson WB, Wyatt RJ, Bunney WE Jr (1984): Sleep and affective illness. In Post RM, Ballenger JC (eds), Neurobiology of Mood Disorders. Baltimore: Williams \& Wilkins.
Greden JF, Gardner R, King D, Grunhaus L, Kronfol Z, Carroll BJ (1983): Dexamethasone suppression tests in antidepressant treatment of melancholia. Arch Gen Psychiatry 40:493-500.

Green WJ, Stajduhar PP (1966): The effect of ECT on the sleep-dream cycle in a psychotic depression. $J$ Nerv Ment Dis 143:123-134.

Hawkins DR, Mendels J, Scott J, Bensch G, Teachey W (1967): The psychophysiology of sleep in psychotic depression: A longitudinal study. Psychosomat Med 29:329-344.

Kupfer DJ (1981): EEG, sleep and tricyclic antidepressants in affective disorders. In Usdin E (ed), Clinical Pharmacology in Psychiarry. New York: Elsevier, pp 325-338.

Kupfer DJ, Thase ME (1983): The use of sleep laboratory in the diagnosis of affective disorders. Psychiatr Clin North Am 6:3-25.

Kupfer DJ, Foster FG, Reich L, Thompson KS, Weiss B (1976): EEG sleep changes as predictors in depression. Am J Psychiatry 133:622-626.

Mendels J, Van de Castle RL, Hawkins DR (1974): Electroconvulsive therapy and sleep. In Fink $M$, Kety $S$, McGaugh J, Williams T (eds), Psychobiology of Convulsive Treatment. V.H. Winston and Sons, pp 41-46.

Van de Castle RL, Hawkins D (1969): The effect of electroconvulsive therapy upon sleep patterns of depressed patients. Psychophysiology 6:234.

Zarcone V, Gulevich G, Dement W (1967): Sleep and electroconvulsive therapy. Arch Gen Psychiatry 16:567-573. 